Bài báo khoa hoc

\title{
Đánh giá xu thế và xây dựng kịch bản biến đổi khí hậu cho tỉnh Bình Phước
}

\author{
Lê Hoài Nam ${ }^{1}$, Nguyễn Văn Tín ${ }^{3}$, Hồ Công Toàn ${ }^{2}$, Trần Tuấn Hoàng ${ }^{2}$, Phạm Thanh \\ Long $^{2 *}$ \\ ${ }^{1}$ Trung tâm Quan trắc Môi trường miền Nam; lhnammt@gmail.com; \\ 2 Phân Viện Khoa học Khí tượng Thủy văn và Biến đổi khí hậu; hoangkttv@gmail.com; \\ longpham.sihymete@gmail.com; hocongtoanhdh@gmail.com; \\ ${ }^{3}$ Trường Đại học Tài nguyên và Môi trường TP. HCM; tin.sihymete@gmail.com; \\ * Tác giả liên hệ: longpham.sihymete@gmail.com; Tel.: +84-905 779777.
}

Ban Biên tập nhận bài: 15/7/2020; Ngày phản biện xong: 22/8/2020; Ngày đăng bài: $25 / 9 / 2020$

Tóm tắt: Bài báo này đánh giá xu thế biến đổi diễn ra tại Bình Phước giai đoạn 1981-2018 và xây dựng kịch bản biến đổi khí hậu $(\mathrm{BĐKH})$ cho tỉnh Bình Phước bằng phương pháp chi tiết hóa động lực và dựa trên kết quả kịch bản BĐKH cho Việt Nam năm 2016 của Bộ Tài nguyên và Môi trường. Kết quả cho thấy, xu thế biến khí hậu tại hai trạm quan trắc Đồng Phú và Phước Long khá tương đồng cụ thể: Trong giai đoạn 1981-2018, về nhiệt độ trung bình tại trạm Đồng Phú có xu thế tăng $0,41^{\circ} \mathrm{C} /$ thập kỷ, tại trạm Phước Long có xu thế tăng $0,45^{\circ} \mathrm{C} /$ thập kỷ. Về lượng mưa, tại Đồng Phú có xu thế giảm $1,2 \mathrm{~mm} / \mathrm{năm}$, trong khi đó tại trạm Phước Long có xu thế tăng $2,3 \mathrm{~mm} /$ năm. Đồng thời, kết quả xây dựng kịch bản $\mathrm{BĐKH}$ tại Bình Phước cho thấy, nhiệt độ trung bình trong tương lai có xu thế tăng theo các kịch bản RCP4.5 và RCP8.5: Theo RCP4.5 vào năm 2025 , nhiệt độ trung bình tăng $0,7^{\circ} \mathrm{C}$, vào năm 2030 tăng khoảng $0,9^{\circ} \mathrm{C}$, đến năm 2050 tăng $1,4{ }^{\circ} \mathrm{C}$ và năm 2100 tăng $1,9{ }^{\circ} \mathrm{C}$; theo RCP8.5 nhiệt độ tăng $0,9^{\circ} \mathrm{C}$ vào năm 2025 , tăng $1^{\circ} \mathrm{C}$ và $1,8^{\circ} \mathrm{C}$ vào năm 2030 và năm 2050 và mức tăng cao nhất đến 2100 lến đến $3,6-3,7^{\circ} \mathrm{C}$. Đối với lượng mưa, theo kịch bản RCP4.5 vào năm 2025, 2030 tại Đồng Phú có mức thay đổi 8,7\%, 9,6\%, năm 2050 mức tăng khoảng 9,2\% và năm 2100 lên đến 14,5\%. Trong khi đó, tại trạm Đồng Phú, lượng mưa năm có mức tăng từ $9,9 \%$ đến $16,6 \%$, tương ứng từ năm 2025 đến năm 2100 . Ngoài ra, theo kịch bản RCP8.5, lượng mưa tại Đồng Phú tăng khoảng 9,6\% năm 2025, năm 2030 tăng 10\%, năm 2050 tăng 12,3\%, năm 2100 tăng mạnh với 23,1\%; tại Phước Long, lượng mưa năm tăng khoảng $9,7 \%$ vào năm 2025 , tăng khoảng $9,9 \%$ vào năm 2030 và tăng khoảng $15,3 \%$ (năm 2050) và $26,5 \%$ (năm 2100).

Từ khóa: Biến đổi khí hậu; Xu thế; Kịch bản.

\section{Mở đầu}

Biến đổi khí hậu trong giai đoạn hiện tại là do các hoạt động công nghiệp, xã hội làm phát thải quá mức các khí nhà kính vào bầu khí quyển [1]. Những hoạt động của con người đã tác động lớn đến hệ thống khí hậu, đặc biệt kể từ thời kỳ tiền công nghiệp (khoảng từ năm 1750). Theo Ủy ban liên Chính phủ về biến đổi khí hậu (IPCC), sự gia tăng khí nhà kính kể từ những năm 1950 chủ yếu có nguồn gốc từ các hoạt động của con người. Hay nói cách khác, nguyên nhân chính của sự nóng lên toàn cầu trong giai đoạn hiện nay bắt nguồn từ sự gia tăng khí nhà kính có nguồn gốc từ hoạt động của con người [2]. Hệ quả là $\mathrm{BĐKH} \mathrm{đã} \mathrm{và}$ đang tác động trực tiếp đến đời sống kinh tế-xã hội và môi trường toàn cầu. IPCC đã nghiên 
cứu và xây dựng các kịch bản $\mathrm{BĐKH} \mathrm{từ} \mathrm{những} \mathrm{năm} 1988$ nhằm xác định xu hướng trong tương lai của khí hậu dựa trên mối quan hệ giữa hoạt động kinh tế-xã hội, phát thải nhà kính, BĐKH và mực nước biển dâng theo cơ sở khoa học và có tính tin cậy [3-4]. Năm 1990, IPCC đã lần đầu công bố kịch bản BĐKH trong báo cáo lần thứ nhất và bổ sung vào năm 1992 [4]. Đến năm 2000, IPCC đã đưa ra tập kịch bản thế hệ thứ hai về phát thải khí nhà kính (Special Report on Emission Scenarios-SRES), họ kịch bản này tiếp tục được dùng trong báo cáo lần thứ ba năm 2001 và lần thứ tư năm 2007 [4]. Năm 2013, IPCC công bố kịch bản cập nhật, đường phân bố nồng độ khí nhà kính đại diện (Representative Concentration Pathways$R C P$ ) được sử dụng để thay thế cho các kịch bản SRES trong báo cáo lần thứ năm [2-5].

Trong báo cáo của IPCC và kịch bản Bộ Tài nguyên và Môi trường công bố năm 2016 đã có nhắc đến rằng: Việt Nam là một trong những quốc gia bị ảnh hưởng nặng nề của $\mathrm{BĐKH}$ [2-4]. Trong những năm qua, dưới tác động của $\mathrm{BĐKH,} \mathrm{tần} \mathrm{suất} \mathrm{và} \mathrm{cường} \mathrm{độ} \mathrm{các} \mathrm{thiên} \mathrm{tai}$ ngày càng gia tăng, gây nhiều tổn thất to lớn về người, tài sản, cơ sở hạ tầng, về kinh tế, văn hoá, xã hội, tác động xấu đến môi trường. Tác động của $B Đ K H$ đối với nước ta là rất nghiêm trọng, là nguy cơ hiện hữu cho mục tiêu xóa đói giảm nghèo, cho việc thực hiện các mục tiêu thiên niên kỷ và sự phát triển bền vững của đất nước [4]. Đối với lĩnh vực nghiên cứu về BĐKH ở Việt Nam, lĩnh vực này thực sự được bắt đầu từ những năm 1990 của Viện Khí tượng Thủy văn (nay là Viện Khoa học Khí tượng Thủy văn và Biến đổi khí hậu) với các chuyên gia như: Nguyễn Đức Ngữ, Trịnh Văn Thư, Nguyễn Trọng Hiệu, Vũ Văn Tuấn, Trần Việt Liễn, Nguyễn Duy Chinh, Trần Thục, ... và nhiều chuyên gia khác. Tuy nhiên, vấn đề này chỉ thực sự được quan tâm chú y từ sau năm 2000, đặc biệt từ năm 2009, kịch bản BĐKH và nước biển dâng $(\mathrm{NBD})$ cho Việt Nam được Bộ Tài nguyên và Môi trường công bố lần đầu vào năm 2009 trên cơ sở tổng hợp các nghiên cứu trong và ngoài nước, sau đó tiếp tục được cập nhật vào năm 2012 và cập nhật mới nhất vào năm 2016 [3-4].

Trước các sức ép về tốc độ phát triển kinh tế-xã hội trên địa bàn tỉnh Bình Phước, sự gia tăng các hoạt động của con người tạo ra các khí thải nhà kính, các hoạt động khai thác quá mức bể hấp thụ khí nhà kính như sinh khối, rừng, các hệ sinh thái, ... góp phần gây ra sự BĐKH toàn cầu, thể hiện qua sự gia tăng của nhiệt độ, sự thay đổi của lượng mưa và những diễn biến bất thường của thiên tai, thời tiết cực đoan. Biến đổi khí hậu đã làm thay đổi các giá trị khí tượng thủy văn đặc trưng (trung bình, max, min). Báo cáo này nhằm mục đích đánh giá xu thế biến đổi của các yếu tố khí hậu ở Bình Phước trong điều kiện BĐKH, xây dựng chi tiết kịch bản $\mathrm{B} Đ K H$ cho tỉnh Bình Phước từng năm cụ thể dựa trên kết quả kịch bản BĐKH cho Việt Nam năm 2016, và ngoài ra nhằm tách biệt các tác động của $\mathrm{B} Đ K H$ tại Bình Phước theo quy hoạch kinh tế-xã hội với các mốc thời gian 2025, 2030, 2050, đồng thời phục vụ đánh giá tác động và xây dựng các giải pháp ứng phó phù hợp theo quy hoạch.

\section{Phương pháp nghiên cứu}

\subsection{Giới thiệu khu vục nghiên cưu}

Nghiên cứu được thực hiện trên khu vực tỉnh Bình Phước, là một tỉnh thuộc miền Đông Nam Bộ, có đường biên giới tiếp giáp với Campuchia dài 260,433km (Hình 1). Khu vực nghiên cứu có địa bàn trung chuyển giữa Nam Tây Nguyên và miền Đông Nam Bộ, nên tỉnh có địa hình rất đa dạng, gồm cả địa hình cao nguyên, đồi núi và đồng bằng. Nằm trong vùng kinh tế trọng điểm phía Nam, có vị trí không xa Thành phố Hồ Chí Minh-trung tâm kinh tế lớn nhất của cả nước lại có cửa khẩu thông thương với Campuchia, Bình Phước có rất nhiều cơ hội để phát triển thương mại, du lịch và xuất khẩu,...

Bình Phước nằm trong khu vực có nền nhiệt độ cao đều quanh năm. Nhiệt độ trung bình hằng năm của các khu vực trong tỉnh là $23,0-26,3{ }^{\circ} \mathrm{C}$, nhiệt độ trung bình tháng cao nhất (tháng 4) tại Đồng Phú là $28,30^{\circ} \mathrm{C}$, tại Phước Long là $27,6^{\circ} \mathrm{C}$ và nhiệt độ trung bình tháng thấp nhất (tháng 12 ) tại Đồng Phú là $24,6^{\circ} \mathrm{C}$, tại Phước Long là $23,9^{\circ} \mathrm{C}$. Các cực trị nhiệt độ 
lên xuống khá cao, tại Đồng Phú nhiệt độ tối cao $(\mathrm{Tx})$ lên đến $40,6^{\circ} \mathrm{C}$ và nhiệt độ tối thấp (Tn) xuống đến $11,9^{\circ} \mathrm{C}$; tuy nhiên tần suất xuất hiện thấp $30-40$ năm/1 lần.

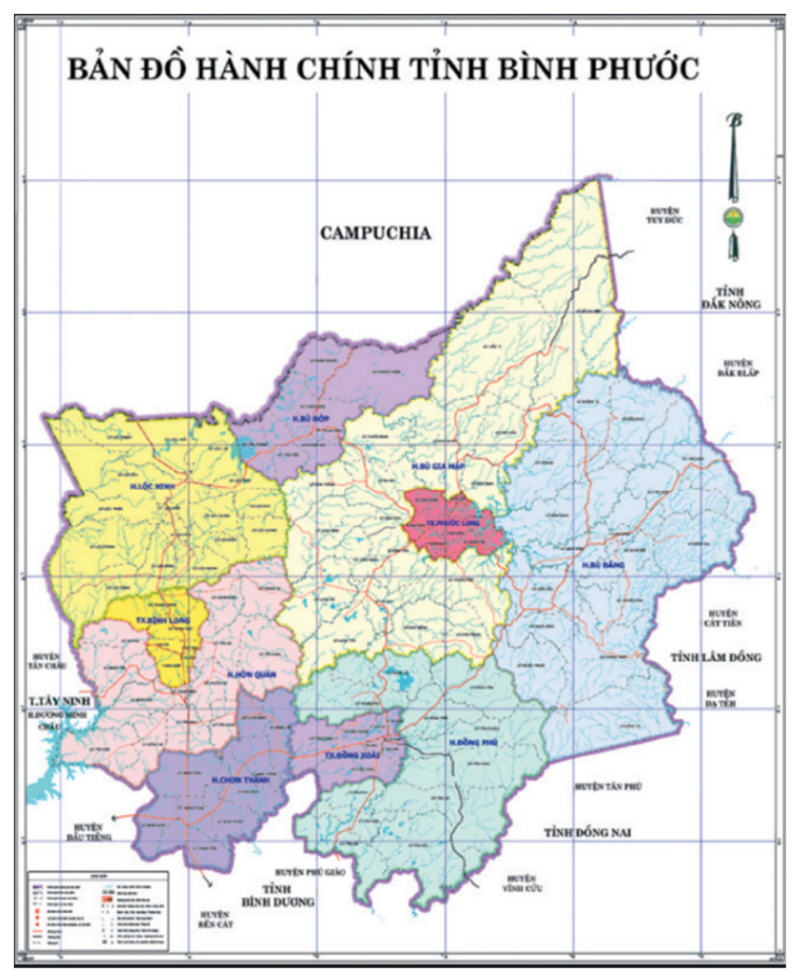

Hình 1. Bản đồ hành chính tỉnh Bình Phước.

\subsection{Phương pháp xác định xu thế Sen'Slop và kiểm nghiệm phi tham số Mann-Kendall}

\subsubsection{Kiểm nghiệm phí tham số Mann-Kendall (M-K test)}

Kiểm nghiệm Mann-Kendall so sánh độ lớn tương đối của các phần tử trong chuỗi dữ liệu, điều này có thể tránh được các giá trị cực đại hoặc cực tiểu cục bộ của chuỗi số liệu. Nếu giả thiết rằng có một dữ liệu theo chuô̂i trình tự thời gian $\left(\mathrm{x}_{1}, \mathrm{x}_{2}, \ldots \mathrm{x}_{\mathrm{n}}\right)$ với $\mathrm{x}_{\mathrm{i}}$ biểu diễn số liệu tại thới điểm i tại mỗi một thời điểm thì mỗi giá trị dữ liệu tại mỗi thời điểm được so sánh với các giá trị trên toàn chuỗi thời gian. Giá trị ban đầu của thống kê Mann-Kendall, $\mathrm{S}$ là 0 (nghĩa là không có xu thế). Nếu một dữ liệu ở một thời điểm sau lớn hơn giá trị của dữ liệu ở một thời điểm nào đó trước đấy, $\mathrm{S}$ được tăng thêm 1 ; và ngược lại. Xét chuỗi $\mathrm{x}_{1}, \mathrm{x}_{2}$, $\ldots, \mathrm{x}_{\mathrm{n}}$ biểu diễn $\mathrm{n}$ điểm dữ liệu trong đó $\mathrm{x}_{\mathrm{j}}$ là giá trị dữ liệu tại thời điểm $\mathrm{j}$. Khi đó chỉ số thống kê Mann-Kendall S [3] được tính bởi:

$$
S=\sum_{i=1}^{N-1} \sum_{j=i+1}^{N} \operatorname{sign}\left(x_{j}-x_{i}\right)
$$

Trong đó

$$
\operatorname{sign}\left(x_{i}-x_{j}\right)\left\{\begin{array}{c}
1 \text { khi } x_{i}-x_{j}>0 \\
0 \text { khi } x_{i}-x_{j}=0 \\
-1 \text { khi } x_{i}-x_{j}<0
\end{array}\right.
$$

Giá trị $\mathrm{S}>0$ chỉ xu thế tăng, $\mathrm{S}<0$ chỉ xu thế giảm.

Tuy nhiên cần phải tính toán xác xuất đi kèm với $\mathrm{S}$ và $n$ để xác định mức ý nghĩa của $\mathrm{xu}$ hướng. Phương sai của $\mathrm{S}$ được tính theo công thức:

$$
\operatorname{VAR}(S)=\frac{1}{18}\left\lceil n(n-1)(2 n+5)-\sum_{p=1}^{g} t_{p}\left(t_{p}-1\right)\left(2 t_{p}+5\right)\right\rceil
$$

Trong đó g là số các nhóm có giá trị giống nhau, $t_{p}$ là số phần tử thuộc nhóm thứ p. Giá trị chuẩn $\mathrm{Z}$ của $\mathrm{S}$ tuân theo định luật phân phối chuẩn. 


$$
\begin{aligned}
& Z=\frac{S-1}{[\operatorname{VAR}(S)]^{1 / 2}}, S>0 \\
& \mathrm{Z}=0, \mathrm{~S}=0 \\
& Z=\frac{S+1}{[\operatorname{VAR}(S)]^{1 / 2}}, S<0
\end{aligned}
$$

$\mathrm{Z}$ có phân phối chuẩn $\mathrm{N}(0,1)$ dùng để kiểm định chuỗi có xu thế hay không với mức ý nghĩa cho trước (trong nghiên cứu này dùng $\propto=0,1$ ).

\subsubsection{Phương pháp xu thế Sen (Sen’s slope)}

Để xác định độ lớn của xu thế chuỗi $\mathrm{Q}$ (độ dốc đường xu thế) ta dùng ước lượng Sen. $\mathrm{Q}$ là median của chuỗi $n(n-1) / 2$ phần tử.

$$
\mathrm{Q}=\operatorname{median}\left\{\frac{x_{j}-x_{i}}{j-i}\right\} \text { với } \mathrm{i}=1,2, \ldots . . \mathrm{n}-1 ; \mathrm{j}>\mathrm{i} \text {. }
$$

$\mathrm{Q}>0$ chuỗi có xu thế tăng và ngược lại.

\subsection{Phương pháp xây dụng kịch bản BĐKH}

Phương pháp chi tiết hóa động lực được sử dụng để xây dựng kịch bản BĐKH độ phân giải cao cho Bình Phước gồm kịch bản trung bình RCP4.5 và kịch bản cao RCP8.5. Bốn mô hình khí hậu khu vực được áp dụng bao gồm: CCAM, RegCM, PRECIS và clWRF. Mỗi mô hình có các phương án tính toán khác nhau dựa trên kết quả tính toán từ các mô hình toàn cầu của IPCC, 2013 (Hình 2) [4].

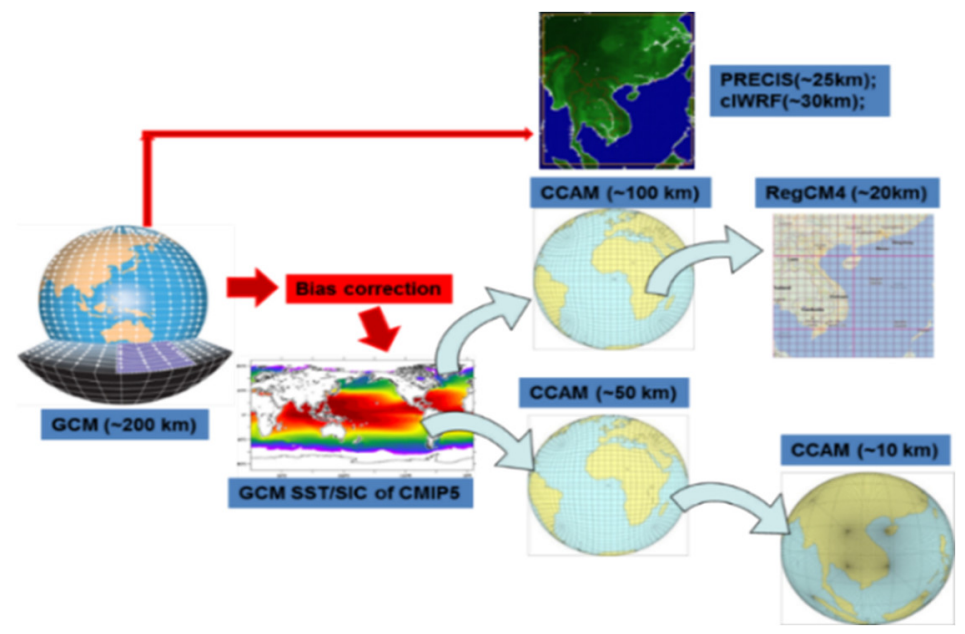

Hình 2. Sơ đồ chi tiết hóa động lực độ phân giải cao [4].

Trong kịch bản BĐKH cho Việt Nam sử dụng: Sự thay đổi của nhiệt độ và mưa được so sánh với thời kỳ cơ sở 1986-2005, đây cũng là giai đoạn được IPCC dùng trong báo cáo lần thứ năm [2-4].

Đối với nhiệt độ:

Đối với lượng mưa:

$$
\Delta T_{\text {future }}=T_{\text {future }}^{*}-\overline{T_{1986-2005}^{*}}
$$

$$
\Delta R_{\text {future }}=\frac{\left(R_{\text {future }}^{*} \overline{R_{1986-2005}^{*}}\right)}{\overline{R_{1986-2005}^{*}}} * 100
$$

Trong đó $\Delta \mathrm{T}_{\text {future }}$ là biến đổi của nhiệt độ trong tương lai so với thời kỳ cơ sở $\left({ }^{\circ} \mathrm{C}\right) ; \mathrm{T}^{*}$ future là nhiệt độ tương lai $\left({ }^{\circ} \mathrm{C}\right) ; \mathrm{T}^{*}{ }_{1986-2005}$ là nhiệt độ trung bình của thời kỳ cơ sở $\left({ }^{\circ} \mathrm{C}\right) ; \Delta \mathrm{R}$ future là biến đổi của lượng mưa trong tương lai so với thời kỳ cơ sở (\%); $\mathrm{R}^{*}$ future là lượng mưa tương lai $(\mathrm{mm}) ; \mathrm{R}^{*}{ }_{1986-2005}$ là lượng mưa trung bình của thời kỳ cơ sở $(\mathrm{mm})$. 
Mô hình khí hậu động lực có ưu điểm là mô phỏng tốt các quá trình vật lý và hóa học trong khí quyển, tuy nhiên khó phản ánh được các yếu tố địa phương và mô hình đều tồn tại sai số hệ thống nhất định. Để khắc phục điều này, phương pháp thống kê (hiệu chỉnh phân vị-Quantile Mapping) được áp dụng để hiệu chỉnh kết của mô hình theo số liệu thực đo tại trạm quan trắc [6-7].

Qua phân tích và đánh giá sai số kế thừa từ kịch bản BĐKH và NBD năm 2016 [4]: đã chọn được tổng cộng 12 phương án tính toán tốt nhất của bốn mô hình để xây dựng kịch bản BĐKH chi tiết cho tỉnh Bình Phước. Trong đó, đối với nhiệt độ là tổ hợp 08 phương án của ba mô hình (04 phương án CCAM, 03 phương án PRECIS và 01 phương án clWRF); đối với lượng mưa là tổ hợp 03 phương án của mô hình PRECIS [4]. Đánh giá kết quả của 5 mô hình khí hậu được áp dụng ở Việt Nam cho thấy, các mô hình đều mô phỏng khá tốt nhiệt độ trên hầu hết các khu vực của Việt Nam, chỉ riêng mô hình clWRF có sai số hệ thống tương đối lớn. Kết quả tính toán về lượng mưa có sự khác biệt giữa các mô hình đối với các vùng khí hậu của Việt Nam. Trong đó, mô hình PRECIS cho kết quả tính toán tốt hơn so với các mô hình còn lại [8]. Vì vậy, để đảm bảo mức độ tin cậy, kịch bản biến đổi khí hậu đối với nhiệt độ được xây dựng theo kết quả tính toán của cả 5 mô hình, kịch bản biến đổi của lượng mưa được xây dựng dựa trên kết quả tính toán từ 3 phương án của mô hình PRECIS.

\subsection{Phuơng pháp lập bản đồ}

Bản đồ nhiệt độ, lượng mưa theo các kịch bản BĐKH RCP4.5 và RCP8.5 được thành lập bằng công nghệ hệ thống thông tin địa lý (GIS) dựa trên công cụ bản đồ như Mapinfo, ArcGIS 10.1. Phương pháp này nhằm trích lọc các kết quả của mô hình phục vụ cho quản lý và khai thác thông tin, từ đó chồng ghép để xây dựng bản đồ biến đổi nhiệt độ, lượng mưa cho tỉnh Bình Phước.

\subsection{Số liệu sử dụng}

Số liệu được sử dụng bao gồm: (i) Số liệu tính toán từ bốn mô hình khí hậu khu vực, với thời kỳ cơ sở là giai đoạn 1986-2005, kịch bản BĐKH theo các mốc thời gian năm 2025, năm 2030, năm 2050 và năm 2100 theo kịch bản $\mathrm{RCP} 4.5, \mathrm{RCP} 8.5$; (ii) Số liệu quan trắc về nhiệt độ lượng mưa tại trạm Đồng Phú và Phước Long từ năm 1980 đến năm 2018.

\section{Kết quả và thảo luận}

\subsection{Xu thế biến đổi khi hậu}

Hình 3 biểu thị biến trình nhiệt độ trung bình năm tại Đồng Phú và Phước Long. Kết quả cho thấy nhiệt độ trung bình tại Đồng Phú có xu thế tăng trong giai đoạn 1981-2018 với tốc độ tăng khoảng $0,41^{\circ} \mathrm{C} /$ thập kỷ; tại Phước Long, nhiệt độ trung bình có xu thế tăng $(0,45$ ${ }^{\circ} \mathrm{C} /$ thập kỷ), tốc độ xu thế khá tương đồng với trạm Đồng Phú.
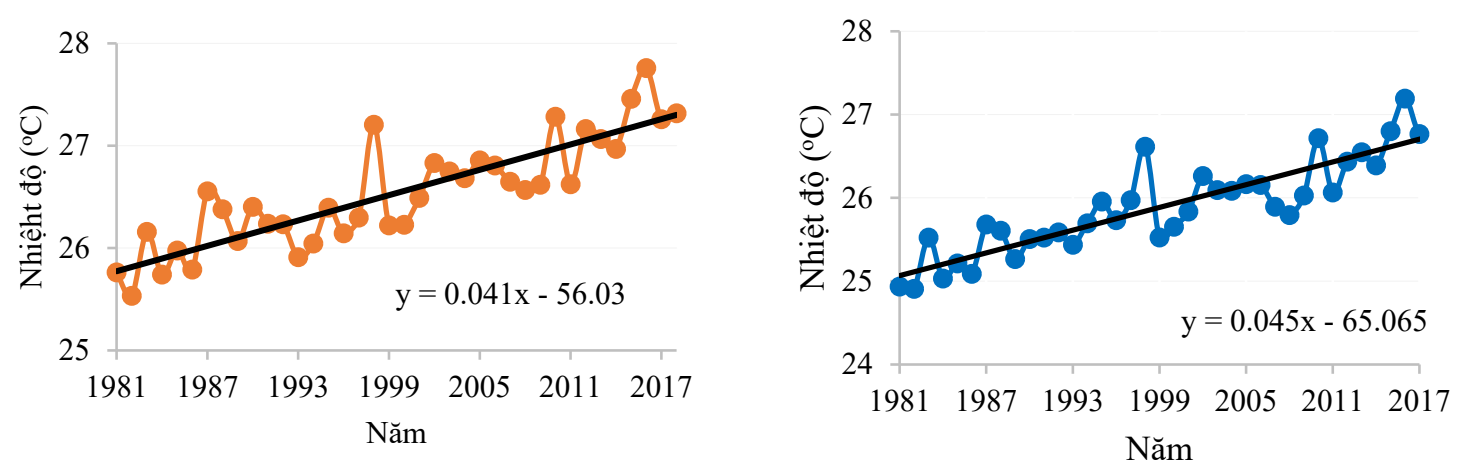

Hình 3. Xu thế biến đổi của nhiệt độ tại Đồng Phú (trái) và Phước Long (phải). 

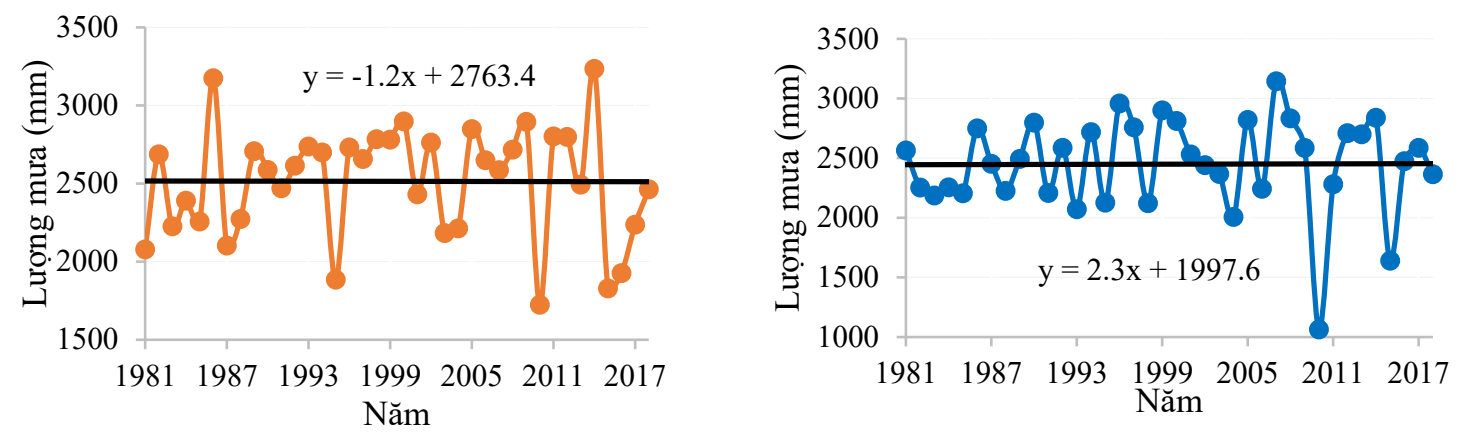

Hình 4. Xu thế biến đổi của lượng mưa tại Đồng Phú (trái) và Phước Long (phải).

Hình 4 thể hiện xu thế biến đổi của lượng mưa ở Bình Phước, kết quả cho thấy tại Đồng Phú lượng mưa giảm 1,2 mm/năm, tương tự tại Phước Long, lượng mưa năm có xu thế tăng $2,3 \mathrm{~mm} / \mathrm{năm}$. Trong khi lượng mưa năm tại Phước Long có xu thế giảm và lượng mưa năm tại Đồng Phú có xu thế tăng, nhưng mức tăng không lớn.

Để đánh giá mức độ tin cậy, bài báo sử dụng kiểm nghiệm $\mathrm{M}-\mathrm{K}$ test với mức ý nghĩa $5 \%$ (xác suất phạm sai lầm loại I không quá 5\%). Kết quả cho thấy với nhiệt độ trung bình tại Đồng Phú và Phương Long thỏa mãn ý nghĩa thống kê $(\propto<0,05)$, đối với lượng mưa năm tại Đồng Phú và Phước Long, kiểm định $\mathrm{M}-\mathrm{K}$ test cho thấy $\propto>0,05$ cho thấy hàm xu thế tăng/giảm của lượng mưa ở Bình Phước không đảm bảo độ tin cậy thống kê (Bảng 1).

Bảng 1. Kiểm nghiệm Mann-Kendall (M-K test) hàm xu thế.

\begin{tabular}{lrrrr}
\hline \multirow{2}{*}{ Thông số kiểm định } & \multicolumn{2}{c}{ Nhiệt độ } & \multicolumn{2}{c}{ Lượng mưa } \\
\cline { 2 - 5 } & \multicolumn{1}{c}{ Đồng Phú } & Phước Long & Đồng Phú & Phước Long \\
\hline N & 38 & 39 & 38 & 39 \\
Min & 25.5 & 24.9 & 1724 & 1064 \\
Max & 27.8 & 27.2 & 3234 & 3144 \\
Mean & 26.54 & 25.89 & 2514 & 2449 \\
Standard Deviation (SD) & 0.544 & 0.576 & 357.6 & 384.8 \\
M-K Test Value (S) & 465 & 543 & 63 & 63 \\
Var(S) & 79.25 & 82.48 & 79.54 & 82.67 \\
$\propto$ & $2.3851 \mathrm{E}-9$ & $2.500 \mathrm{E}-11$ & 0.218 & 0.227 \\
\hline
\end{tabular}

Chú thích: $\mathrm{SD}$ là độ lệch chuẩn; Var $(\mathrm{S})$ là độ lệch chuẩn của $\mathrm{S} ; \mathrm{Z}$ là giá trị chuẩn của $\mathrm{S} ; \propto$ là mức ý nghĩa.

\subsection{Kịch bản BĐKH tại tỉnh Bình Phước}

\subsubsection{Kịch bản biến đổi nhiệt độ trung bình}

Hình 5 thể hiện kịch bản BĐKH về nhiệt độ trung bình cả năm tại 02 trạm Đồng Phú và Phước Long theo kịch bản RCP4.5. Kết quả mức độ biến đổi tương đồng tại trạm Đồng Phú và Phước Long, mức độ biến đổi vào năm 2025 tăng $0,7^{\circ} \mathrm{C}$, năm 2030 tăng khoảng $0,9^{\circ} \mathrm{C}$ năm 2050 tăng $1,4^{\circ} \mathrm{C}$ và năm 2100 nhiệt độ tăng $1,9^{\circ} \mathrm{C}$ so với giai đoạn nền.

Tương tự như kịch bản RCP4.5, nhiệt độ trung bình theo kịch bản RCP8.5 (Hình 6) có mức biến đổi tăng trong tương lai qua từng môc thời gian cụ thể. Tuy nhiên, mức độ ở kịch bản này tăng cao hơn so với kịch bản $\mathrm{RCP} 4.5$, cụ thể vào năm 2025 , nhiệt độ trung bình tăng $0,9^{\circ} \mathrm{C}$, vào năm 2030 mức tăng khoảng $1^{\circ} \mathrm{C}$, đến năm 2050 tăng $1,8{ }^{\circ} \mathrm{C}$ và năm 2100 tăng $3,6^{\circ} \mathrm{C}$ tại Đồng Phú và $3,7^{\circ} \mathrm{C}$ tại Phước Long. 


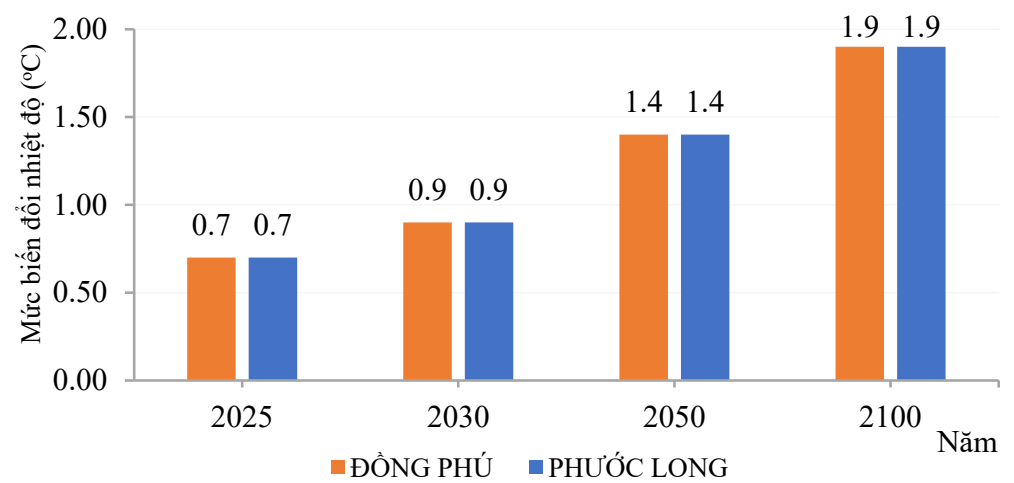

Hình 5. Kịch bản BĐKH về nhiệt độ trung bình khu vực tỉnh Bình Phước theo kịch bản RCP4.5.

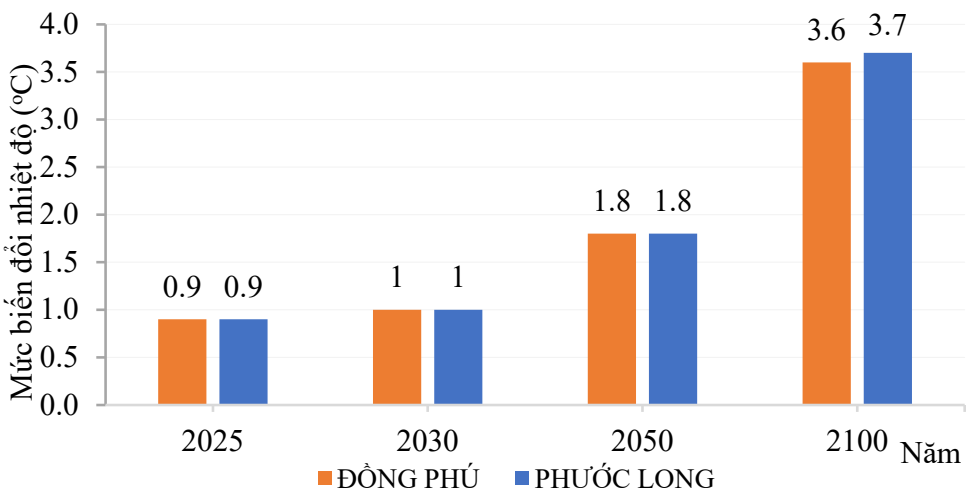

Hình 6. Kịch bản BĐKH về nhiệt độ tại trung bình khu vực tỉnh Bình Phước theo kịch bản RCP8.5.

Phân bố không gian về mức độ biến đổi nhiệt độ trung bình khu vực tỉnh Bình Phước năm 2025, năm 2030, năm 2050 và năm 2100 theo kịch bản $\mathrm{RCP} 4.5$ và $\mathrm{RCP} 8.5$ được thể hiện ở hình Hình 7, Hình 8, Hình 9 và Hình 10.

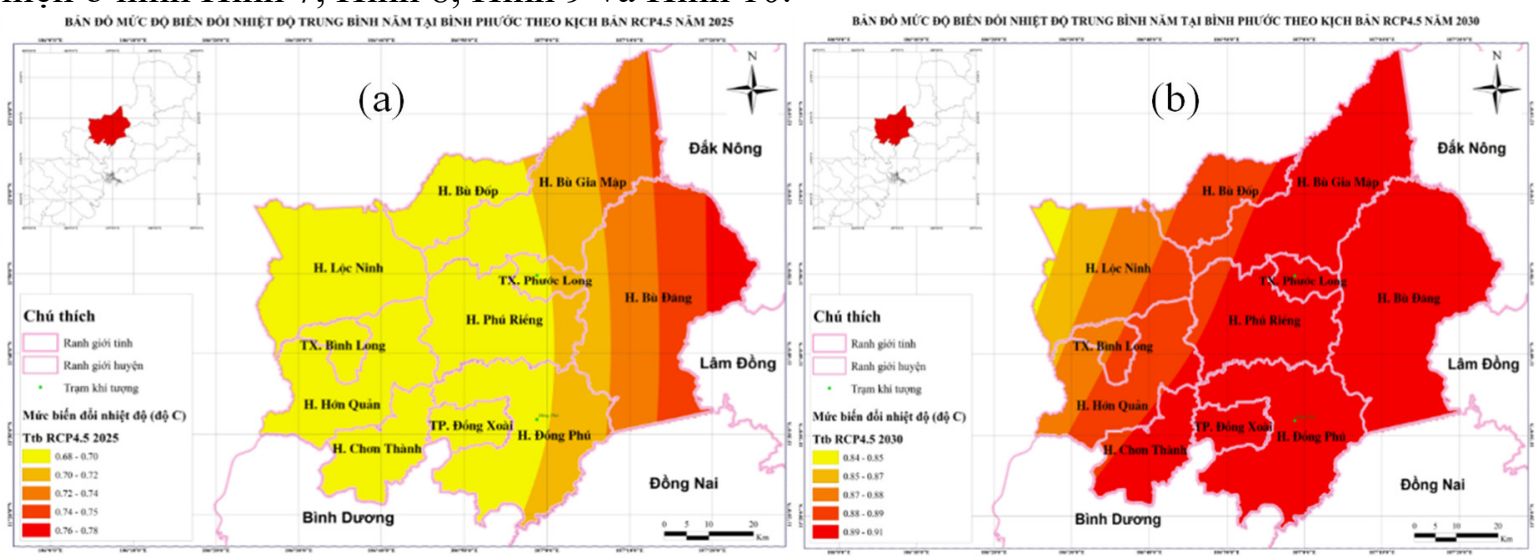

Hình 7. Phân bố mức độ biến đổi nhiệt độ trung bình tại Bình Phước năm 2025 (a) và năm 2030 (b) theo kịch bản RCP4.5.

Theo kịch bản RCP4.5, vào năm 2025, 1/3 tỉnh Bình Phước ở trong mức độ biến đổi nhiệt độ khoảng $0,72-0,78^{\circ} \mathrm{C}$, cao nhất thuộc huyện Bù Đăng và Bù Gia Mập, tiếp đến là TX. Phước Long và huyện Đồng Phú, Bù Đốp. Mức độ biết đổi nhiệt độ tăng thấp nhất khoảng $0,68-0,70^{\circ} \mathrm{C}$ thuộc các huyện phía Tây như Lộc Ninh, Hớn Quản, Chơn Thành, TX. Bình Long, TP. Đồng Xoài. Vào năm 2030, hơn 2/3 tỉnh ở trong mức độ biến đổi nhiệt độ trung bình từ $0,89-0,91^{\circ} \mathrm{C}$, chỉ còn một phần nhỏ huyện Lộc Ninh ở trong mức độ biến đổi dưới $0,88^{\circ} \mathrm{C}$. Vào năm 2050 , nhiệt độ trung bình năm tỉnh Bình Phước có mức biến đổi từ $1,39-1,40^{\circ} \mathrm{C}$, đến cuối thế kỷ vào năm 2100 , mức biển đổi trên toàn tỉnh là $1,9^{\circ} \mathrm{C}$. 

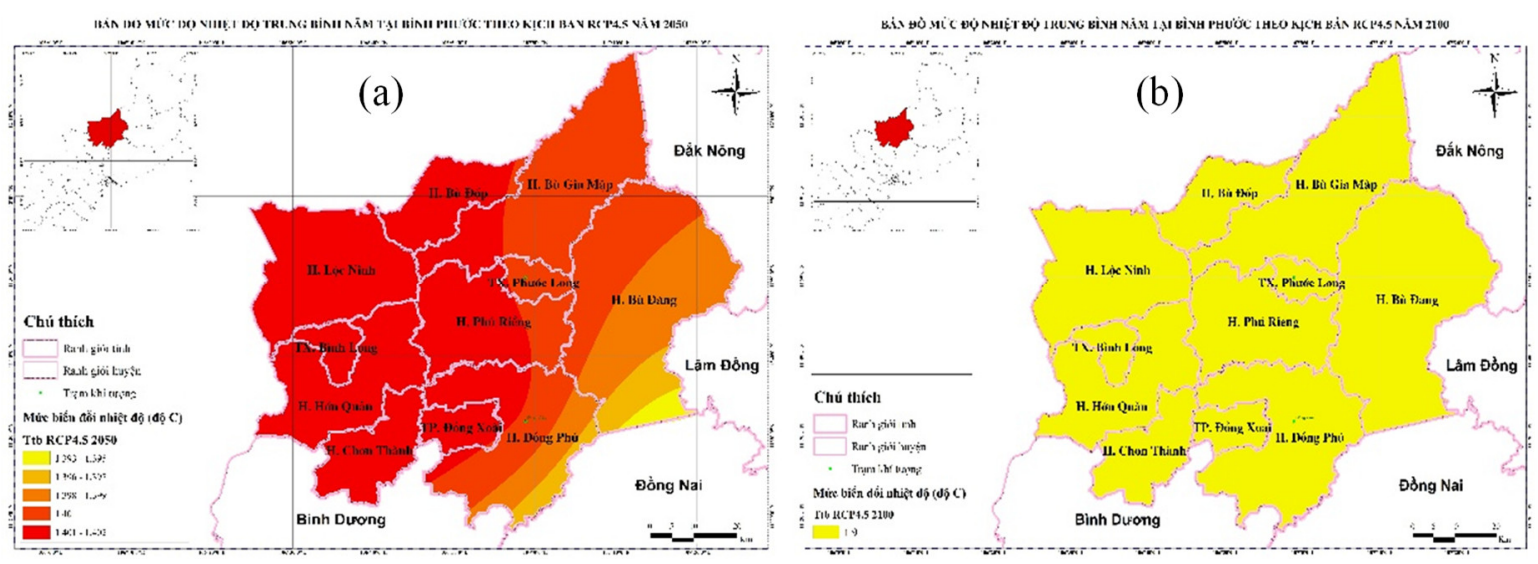

Hình 8. Phân bố mức độ biến đổi nhiệt độ trung bình tại Bình Phước năm 2050 (a) và năm 2100 (b) theo kịch bản RCP4.5.
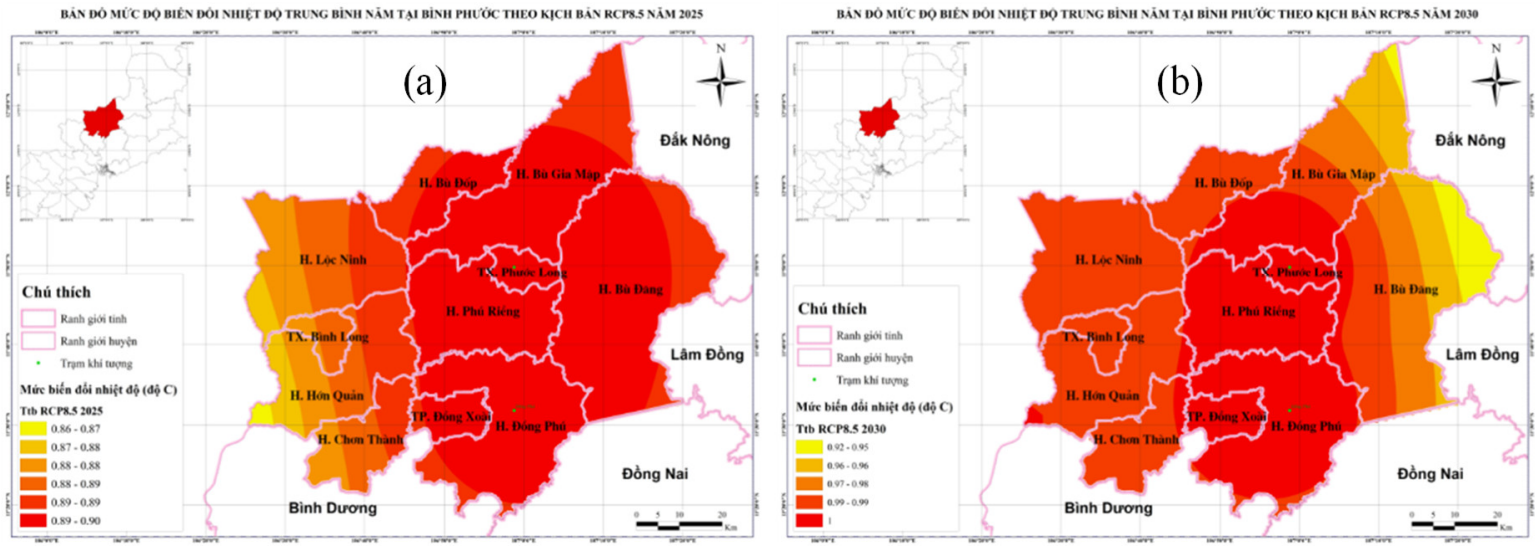

Hình 9. Phân bố mức độ biến đổi nhiệt độ trung bình tại Bình Phước năm 2025 (a) và năm 2030 (b) theo kịch bản RCP8.5.
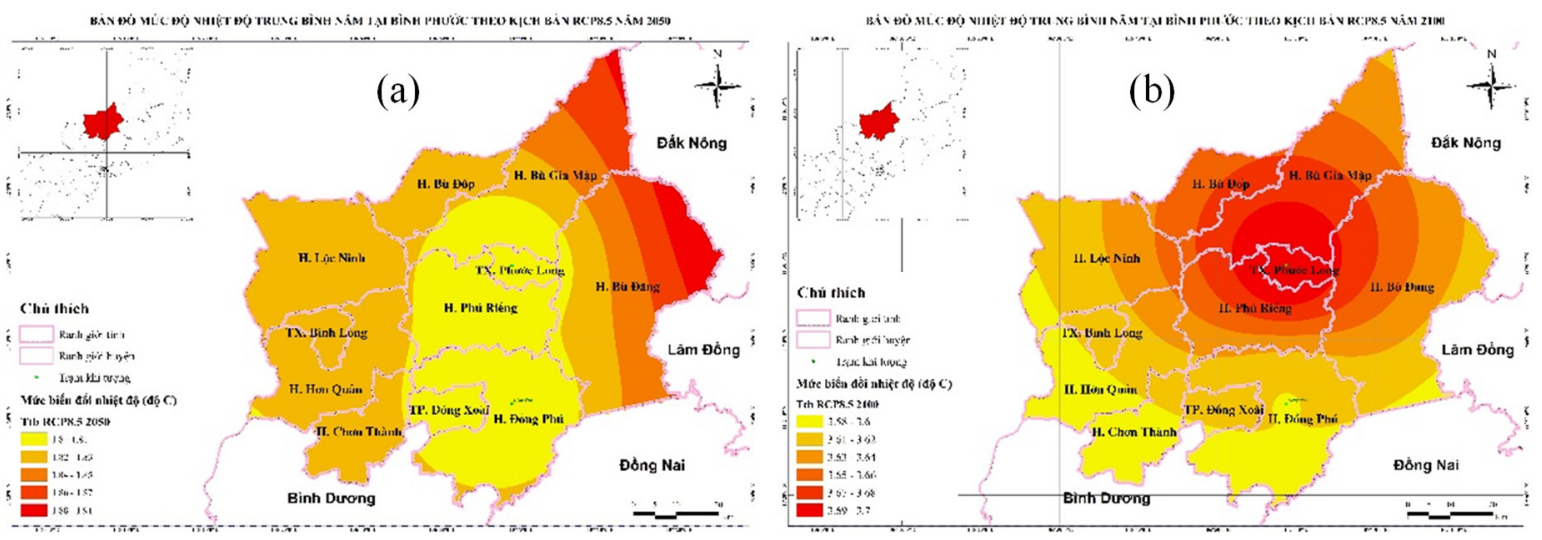

Hình 10. Phân bố mức độ biến đổi nhiệt độ trung bình tại Bình Phước năm 2050 (a) và năm 2100 (b) theo kịch bản RCP8.5.

Theo kịch bản RCP8.5, vào năm 2025, hơn 2/3 tỉnh Bình Phước ở trong mức độ biến đổi nhiệt độ khoảng $0,88^{\circ} \mathrm{C}-0,9^{\circ} \mathrm{C}$. Mức độ biết đổi nhiệt độ tăng thấp khoảng $0,84^{\circ} \mathrm{C}-0,87^{\circ} \mathrm{C}$ thuộc các huyện phía Tây như Lộc Ninh, Hớn Quản, Chơn Thành và TX. Bình Long. Vào năm 2030, hơn 2/3 tỉnh, chiếm toàn bộ các huyện thị phía Tây của tỉnh ở trong mức độ biến đổi nhiệt độ trung bình khoảng $1^{\circ} \mathrm{C}$, chỉ còn một phần nhỏ phía Đông của tỉnh ở trong mức độ biến đổi $0,92^{\circ} \mathrm{C}-0.96{ }^{\circ} \mathrm{C}$. Vào năm 2050 , nhiệt độ trung bình năm có mức biến đổi từ 1,8 ${ }^{\circ} \mathrm{C}$ đến $1,9^{\circ} \mathrm{C}$, nhưng vào năm 2100 , nhiệt độ trung bình năm có mức biến đổi $3,6-3,7{ }^{\circ} \mathrm{C}$, coa hơn rất nhiều so với các kịch bản khác. 


\subsubsection{Kịch bản biến đổi lượng mưa}

Theo kịch bản RCP4.5 (Hình 11), về lượng mưa cả năm cho thấy cà hai trạm đều có xu thế tăng trong tương lai. Năm 2025, 2030 tại Đồng Phú có $8,7 \%$ và $9,6 \%$, và năm 2050 tăng khoảng 9,2\%, năm 2100 lên đến 14,5\%. Tại Phước Long, lượng mưa năm có mức tăng cao hơn hẳn tại Đồng Phú, năm 2025,2030 tại Phước Long tăng khoảng $9,9 \%$ và $11,3 \%$, vào năm 2050 tăng khoảng 10,4 và đến năm 2100 tăng lến 16,6\% so với thời kỳ cơ sở 1986-2005.

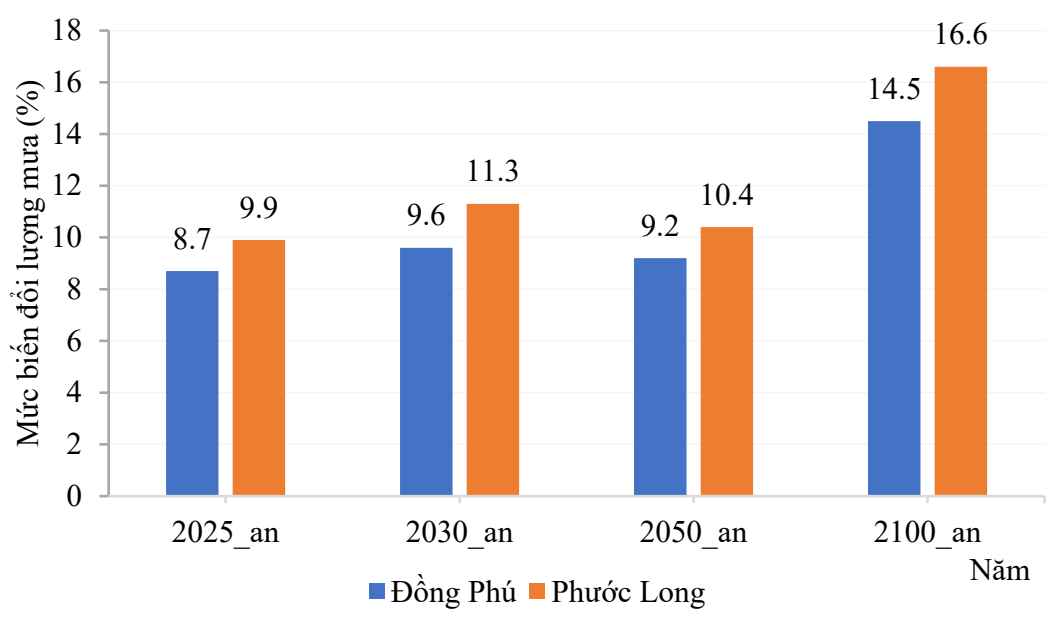

Hình 11. Kịch bản BĐKH về lượng mưa khu vực tỉnh Bình Phước theo kịch bản RCP4.5.

Theo kịch bản RCP8.5 (Hình 12), lượng năm cả năm có xu thế tăng đều ở 2 trạm. Tại Đồng Phú, năm 2025 và năm 2030 tăng lần lượt $9,6 \%$ và $10 \%$, năm 2050 tăng khoảng $12,3 \%$, năm 2100 tăng mạnh với 23,1\%. So với mùa mưa, cả năm ở trạm Phước Long lại tăng cao hơn so với Đồng Phú. Phước Long cả năm 2025 tăng 9,7\%( cao hơn $0,1 \%$ so với ĐP), năm 2030 tăng 9,9\% (thấp hơn 1\%), năm 2050 tăng 15,3\% (cao hơn 3\%), năm 2100 tăng 26,5\% (cao hơn 3,4\%).

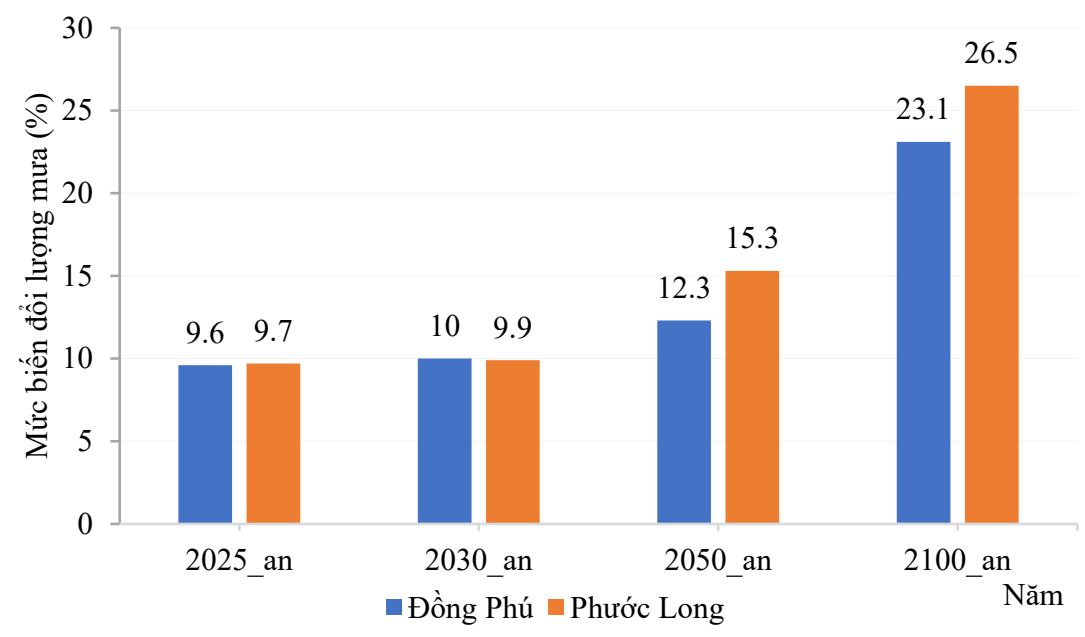

Hình 12. Kịch bản BĐKH về lượng mưa khu vực tỉnh Bình Phước theo kịch bản RCP8.5.

Hình 13a-13d thể hiện mức độ biến đổi lượng mưa vào năm 2025, năm 2030, năm 2050 và năm 2100 theo kịch bản RCP4.5. Lượng mưa năm dao động từ trong khoảng 7,5\% đến 12,4\% năm 2025 theo RCP4.5. Lượng mưa biến đổi tằng từ 8,4-14,2\%, mức độ biến đổi lượng mưa năm 2030 theo RCP4.5 cao hơn so với năm 2025 từ $1-2 \%$. Vào năm 2050 , mức biến đổi lượng mưa khoảng 8,2-13,6\%. Vào năm 2100, lượng mưa năm tỉnh Bình Phước có mức biến đổi rất lớn khoảng 14,5-16,6\%. Về mặt phân bố không gian cả RCP4.5 đang có xu hướng tăng dần theo hướng từ phía Nam-Bắc. 

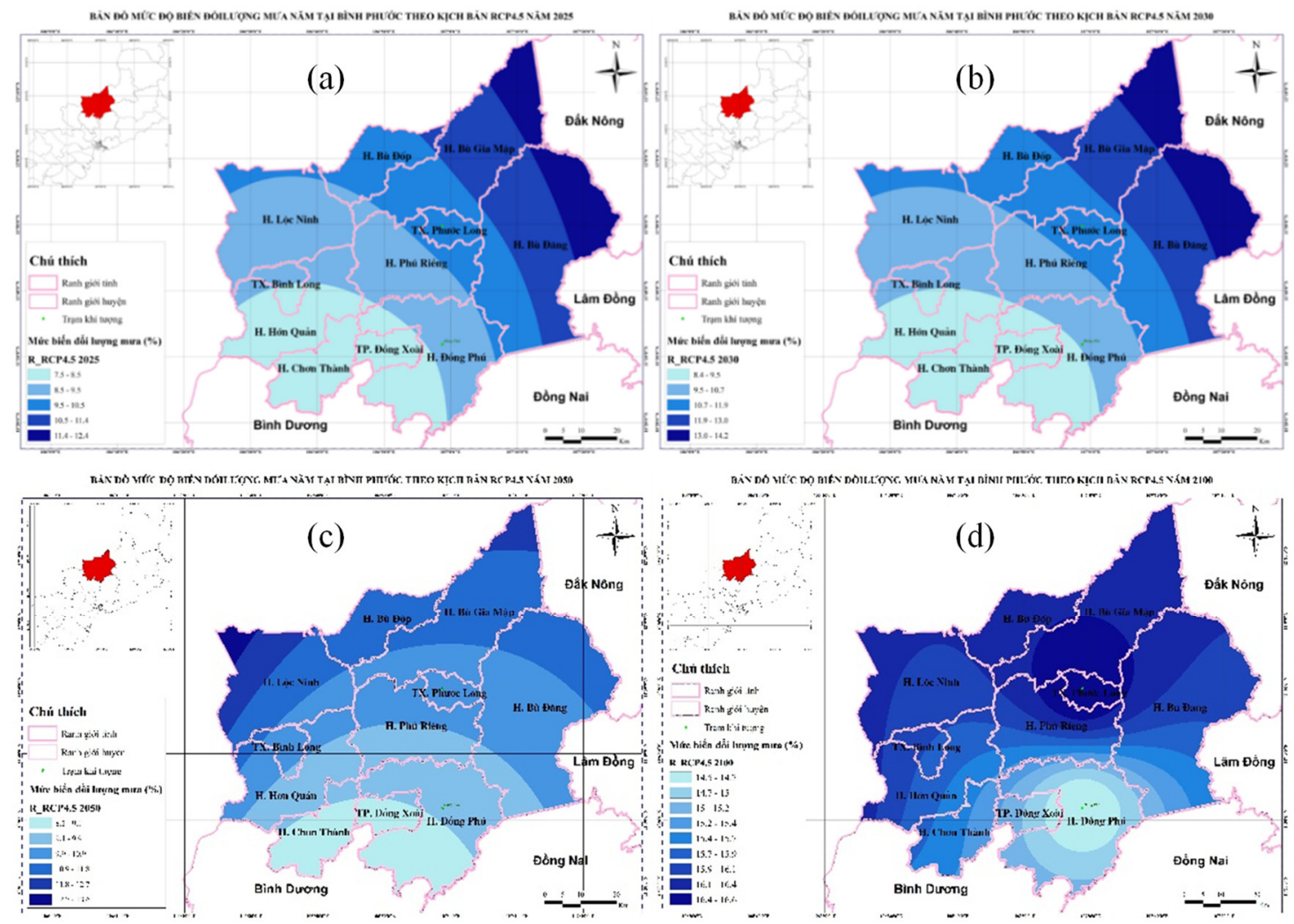

Hình 13. Phân bố mức độ biến đổi lượng mưa tại Bình Phước năm 2025 (a); năm 2030 (b); năm 2050 (c); năm 2100 (d) theo kịch bản RCP4.5.
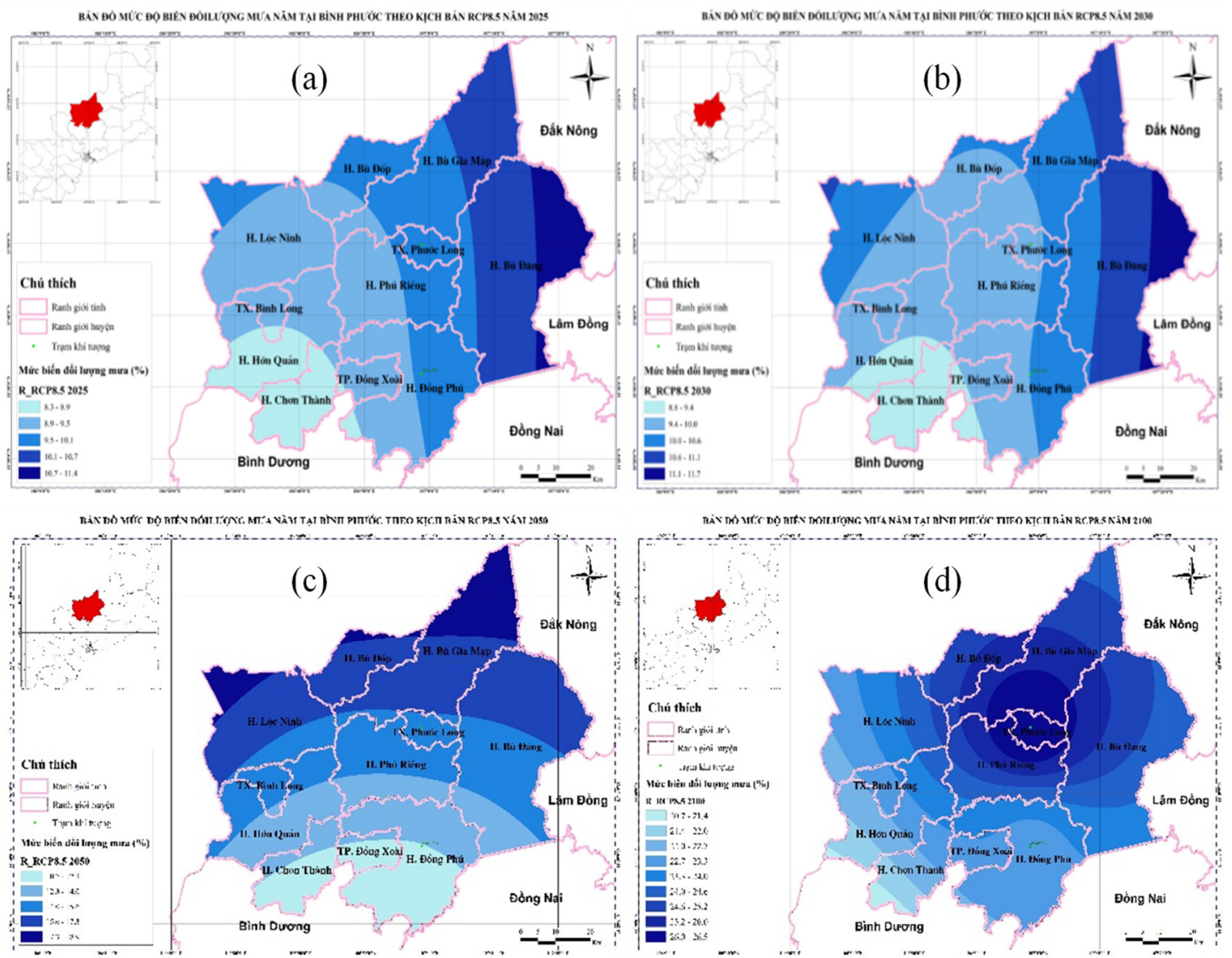

Hình 14. Phân bố mức độ biến đổi lượng mưa tại Bình Phước năm 2025 (a); năm 2030 (b); năm 2050 (c); năm 2100 (d) theo kịch bản RCP8.5. 
Hình 14a-14d thể hiện mức độ biến đổi lượng mưa theo kịch bản RCP8.5. Lượng mưa năm dao động từ trong khoảng $8,3 \%$ đến $11,4 \%$, mức độ biến đổi lượng mưa theo RCP8.5 thấp hơn so với RCP4.5 ̛̛̉ hai mốc thời gian là năm 2025 và năm 2030 . Vào năm 2050 và năm 2100 , mức biến đổi lượng mưa lần lượt trong khoảng $10,7-18,9 \%$ và $20,7-26,5 \%$. Về mặt phân bố không gian ở kịch bản RCP8.5 đang có xu hướng tăng giống với phân bố mức độ biến đổi lượng mưa ở kịch bản RCP4.5 theo hướng từ phía Nam lên phía Bắc.

\section{Kết luận}

Bài báo đã đánh giá xu thế BĐKH giai đoạn 1981-2018 và xây dựng kịch bản BĐKH về nhiệt độ và lượng mưa tại Bình Phước. Kết quả cho thấy nhiệt độ trung bình tại Đồng Phú có xu thế tăng trong giai đoạn 1981-2018 với tốc độ tăng khoảng $0,41{ }^{\circ} \mathrm{C} /$ thập kỷ, tại Phước Long, nhiệt độ trung bình năm có xu thế tăng $\left(0,45^{\circ} \mathrm{C} /\right.$ thập kỷ $)$. Về lượng mưa, tại trạm Đồng Phú có xu thế giảm 1,2 mm/năm, tại trạm Phước Long có xu thế tăng $2,3 \mathrm{~mm} / \mathrm{năm}$, tốc độ tăng tại Phước Long nhanh hơn so với Đồng Phú.

Kịch bản $\mathrm{BĐKH}$ về nhiệt độ trung bình cả năm tại 02 trạm Đồng Phú và Phước Long theo kịch bản RCP4.5. Kết quả cho mức độ biến đổi tương đồng tại Đồng Phú và Phước Long, mức độ biến đổi vào năm 2025 tăng $0,7^{\circ} \mathrm{C}$, năm 2030 tăng khoảng $0,9^{\circ} \mathrm{C}$, năm 2050 tăng $1,4^{\circ} \mathrm{C}$ và năm 2100 nhiệt độ tăng $1,9^{\circ} \mathrm{C}$ so với giai đoạn nền $1986-2005$. Theo $\mathrm{RCP} 8.5$ mức độ biến đổi nhiệt độ tăng trong tương lai theo các giai đoạn, mức độ tăng cao hơn so với kịch bản $\mathrm{RCP} 4.5$, cụ thể vào năm 2025 nhiệt độ trung bình tăng $0,9^{\circ} \mathrm{C}$, vào năm 2030 tăng khoảng $1^{\circ} \mathrm{C}$, đến năm 2050 tăng $1,8^{\circ} \mathrm{C}$ và năm 2100 tăng $3,6^{\circ} \mathrm{C}$ tại Đồng Phú và $3,7^{\circ} \mathrm{C}$ tại Phước Long. Theo kịch bản RCP8.5, lượng năm cả năm có xu thế tăng đều ở 02 trạm. Tại trạm Đồng Phú, lượng mưa năm năm 2025 tăng 9,6\%, năm 2030 tăng 10\%, năm 2050 tăng 12,3\%, năm 2100 tăng mạnh với 23,1\%. Ở trạm Phước Long, lượng mưa năm tăng cao hơn so với Đồng Phú, năm 2025, tăng 9,7\% (cao hơn $0,1 \%$ so với Đồng Phú), năm 2030 tăng 9,9\% (thấp hơn 1\% so với Đồng Phú), năm 2050 tăng 15,3\% (cao hơn 3\% so với Đồng Phú) và năm 2100 tăng 26,5\% (cao hơn 3,4\% so với Đồng Phú). Về mặt phân bố không gian, lượng mưa năm đang có xu hướng tăng dần theo hướng từ phía Nam lên phía Bắc ở cả kịch bản trung bình RCP4.5 và cao RCP8.5.

Đóng góp của tác giả: Xây dựng ý tưởng nghiên cứu: L.H.N., P.T.L.; Lựa chọn phương pháp nghiên cứu: L.H.N., P.T.L., T.T.H.; Xử lý số liệu: N.V.T., H.C.T.; Tính toán: N.V.T., H.C.T.; Phân tích kết quả: L.H.N., N.V.T., H.C.T.; Viết bản thảo bài báo: L.H.N., N.V.T., H.C.T.; Chỉnh sửa bài báo: H.C.T.

Lời cảm ơn: Nghiên cứu này được thực hiện dưới sự tài trợ của đề tài nghiên cứu khoa học cấp Tỉnh là đề tài: "Đánh giá ảnh hưởng của $\mathrm{B} Đ K H$ đến biến động diện tích và cơ cấu sử dụng đất, tiềm năng phát triển kinh tế xã hội, tiềm năng khai thác các loại tài nguyên khoáng sản trên địa bàn tỉnh Bình Phước".

Lời cam đoan: Tập thể tác giả cam đoan bài báo này là công trình nghiên cứu của tập thể tác giả, chưa được công bố ở đâu, không được sao chép từ những nghiên cứu trước đây; không có sự tranh chấp lợi ích trong nhóm tác giả.

\section{Tài liệu tham khảo}

1. IPCC. Climate Change 2007: The Physical Science Basis. Contribution of Working Group I to the Fourth Assessment Report of the Intergovernmental Panel on Climate Change, 2007.

2. IPCC. Climate Change 2013: The Physical Science Basis. Contribution of Working Group I to the Fifth Assessment Report of the Intergovernmental Panel on Climate Change, 2013. 
3. Bộ Tài nguyên Môi trường. Kịch bản Biến đổi khí hậu, nước biển dâng cho Việt Nam, 2012.

4. Bộ Tài nguyên Môi trường. Kịch bản Biến đổi khí hậu, nước biển dâng cho Việt Nam, 2016.

5. Wayne, G., 2013: The beginner's guide to Representative Concentration Pathways.

6. Viện Khoa học Khí tượng Thủy văn và Biến đổi khí hậu. Báo cáo tổng kết dự án "Tư vấn kỹ thuật về dữ liệu và phân tích khí hậu hiện tại và tương lai phục vụ công tác quản lý nguồn nước tại tỉnh Hà Tĩnh", 2016.

7. Amengual, A.; Homar, V.; Romero, R.; Alonso, S.; Ramis, C. A Statistical Adjustment of Regional Climate Model Outputs to Local Scales: Application to Platja de Palma, Spain. J. Climate 2012, 25, 939-957. https://doi.org/10.1175/JCLID-10-05024.1

8. Mishra, B.K.; Herath, S. Assessment of Future Floods in the Bagmati River Basin of Nepal Using Bias-Corrected Daily GCM Precipitation Data. J. Hydrol. Eng. 2014, 20, 05014027. https://doi.org/10.1061/(ASCE)HE.1943-5584.0001090.

\title{
Constructing climate change scenarios for Binh Phuoc province
}

\section{Le Hoai Nam', Nguyen Van Tin ${ }^{3}$, Ho Cong Toan ${ }^{2}$, Tran Tuan Hoang ${ }^{2}$, Pham Thanh Long $^{2}$}

${ }^{1}$ Southern Center for Environmental Monitoring; lhnammt@gmail.com;

${ }^{2}$ Sub-Institute of Hydrometeogology and Climate change; hoangkttv@gmail.com; longpham.sihymete@gmail.com; hocongtoanhdh@gmail.com;

${ }^{3}$ Ho Chi Minh University of Natural Resources and Enviroment; tin.sihymete@gmail.com;

\begin{abstract}
This paper assesses the trend of climate change in Binh Phuoc from 1981-2018 and building climate change scenarios for Binh Phuoc province which follow dynamic detailing method and base on climate change scenarios for Viet Nam in 2016. The result shows that, in the period from 1981-2018, annual temperature at Dong Phu station tended to increase by $0.41{ }^{\circ} \mathrm{C} /$ decade, at Phuoc Long station, increasing by $0.45{ }^{\circ} \mathrm{C} /$ decade. Regarding rainfall, Dong Phu tended to decrease by $1,2 \mathrm{~mm} /$ year and in Phuoc Long by 2,3 $\mathrm{mm} /$ year. Results of developing the climate change scenario in Binh Phuoc show that the average temperature (Ttb) in the future tends to increase by RCP4.5 and RCP8.5 scenarios. According to RCP4.5 in 2025 , Ttb will increase by $0.7^{\circ} \mathrm{C}$, in 2030 increase by $0,9^{\circ} \mathrm{C}$, up to 2050 to $1.4^{\circ} \mathrm{C}$ and 2100 to increase by $1.9^{\circ} \mathrm{C}$, according to RCP 8.5 temperature increases $0.9^{\circ} \mathrm{C}$ in 2025 , up $1^{\circ} \mathrm{C}$ and $1.8^{\circ} \mathrm{C}$ in 2030 and 2050 and the highest increase to 2100 to 3.7 ${ }^{\circ} \mathrm{C}$. For rainfall: according to RCP4.5 in 2025, 2030 in Dong Phu will increase $8.7 \%$ and $9.6 \%$, and up to $9,2-14.5 \%$ in 2050,2100 , according to RCP8.5 rainfall in Dong Phu will increase in $9.6 \%$ (in 2025), by $10 \%$ and $12,3 \%$ (in 2030 and 2050), highest by $23.1 \%$ in 2100 and 26,5\% (in Phuoc Long).
\end{abstract}

Keywords: Climate change; Trend; Scenarios. 